\title{
Controls on the Distribution of Particulate Trace Metals across the Western Antarctic Peninsula Shelf
}

\author{
OLIVER G. FLANAGAN ${ }^{1}$, AMBER ANNETT ${ }^{1}$, ROBERT M. \\ SHERRELL $^{2}$, JESSICA FITZSIMMONS ${ }^{3}$, DANIEL \\ OHNEMUS $^{4}$ AND MAEVE LOHAN $^{5}$ \\ ${ }^{1}$ University of Southampton \\ ${ }^{2}$ Rutgers University \\ ${ }^{3}$ Texas A\&M University \\ ${ }^{4}$ UGA Skidaway Institute of Oceanography \\ ${ }^{5}$ University of Southamtpon \\ Presenting Author: o.g.flanagan@soton.ac.uk
}

Continental shelves of the Antarctic Peninsula are thought to act as source regions for essential dissolved micronutrients, like iron (Fe) and manganese (Mn), whose low concentrations critically limit primary productivity across much of the Southern Ocean (SO). However, the Western Antarctic Peninsula (WAP) has and likely will continue to experience significant physical and ecosystem change as a consequence of global warming e.g., warming bottom waters, increased ice-sheet melt and further glacial retreat. The resulting impact on the sources and cycling of micronutrients on the WAP shelf and the concomitant impact on the wider SO, due to variations in off-shelf export, remain uncertain. Particulate phases, while not directly bioavailable, remain an integral component of trace metal biogeochemical cycling and, at present, particulate trace metal data from the WAP shelf are very limited.

Here we present the largest spatial dataset to date of total particulate bioactive trace metals, collected from the Palmer Long-Term Ecological Research (Pal-LTER) grid of the WAP shelf in January 2015. Metals in the water column are associated, either inherently or via surface adsorption, with biogenic organic matter and biominerals, lithogenic mineral phases, authigenic $\mathrm{Fe} / \mathrm{Mn}$-oxyhydroxides, and barite. Using Factor Analysis, we characterised 5 identifiable particle associations that account for over $90 \%$ of the variance for 15 measured elements across the shelf. An overall synthesis sheds further light on the role of glacial meltwater in delivering particulate trace metals to Antarctic coastal waters. In addition, we present new evidence from total particulate $\mathrm{Fe}, \mathrm{Cd}, \mathrm{Zn}$ and $\mathrm{P}$ data supporting the hypothesis that iron limits productivity and/or structures the phytoplankton assemblage on the outer WAP shelf in the austral summer. 